\title{
Folk Perception of African American English Regional Variation
}

\author{
David Mitchell, ${ }^{1 *}$ Marivic Lesho, ${ }^{2}$ and Abby Walker ${ }^{3}$ \\ ${ }^{1}$ Metropolitan State University \\ ${ }^{2}$ Universität Bremen \\ ${ }^{3}$ Virginia Polytechnic Institute and State University
}

\begin{abstract}
Contrary to previous "sociolinguistic folklore" that African American (Vernacular) English has a uniform structure across different parts of the US, recent studies have shown that it varies regionally, especially phonologically (Wolfram, 2007; Thomas \& Wassink, 2010). However, there is little research on how Americans perceive AAE variation. Based on a map-labeling task, we investigate the folk perception of AAE variation by 55 participants, primarily African Americans in Columbus, Ohio. The analysis focuses on the dialect regions recognized by the participants, the linguistic features associated with different regions, and the attitudes associated with these beliefs. While the perceived regional boundaries mostly align with those identified by speakers in previous perceptual dialectology studies on American English, the participants consistently identified linguistic features that were specific to AAE. The participants recognized substantial phonological and lexical variation and identified "proper" dialects that do not necessarily sound "white". This study demonstrates the value of considering African Americans' perspectives in describing African American varieties of English.
\end{abstract}

Keywords: African American English, perceptual dialectology, folk perception, regional variation, language attitudes

\section{Introduction}

Until fairly recently, the literature on African American (Vernacular) English has often assumed that it has little regional variation. ${ }^{1}$ For example, while Wolfram \& Schilling-Estes (1998:174-175) recognized that there is some regional variation in the dialect (e.g., Northern metropolitan vs. Southern rural varieties), they wrote that "one of the most noteworthy aspects of AAVE is the common core of features shared across different regions ... the regional differences do not come close to the magnitude of the regional differences that exist across Anglo varieties." However, Wolfram (2007) and Fought (2013) have since cautioned sociolinguists against making assumptions about the uniformity of AAE. Recent work has shown that there is in fact considerable regional variation in the dialect (e.g., studies in Yaeger-Dror \& Thomas, 2010; Lanehart, 2015), but African Americans' perspectives on the issue have gone mostly unexplored.

This study investigates the folk perception of regional variation in African American English (AAE), based on a perceptual dialectology map task conducted primarily with African American participants in Columbus, Ohio. The study was designed to address four main questions. First, it aims to identify the dialectal regions that are salient to the participants, as well as the specific linguistic features that they believe to vary across these regions.

*Address for correspondence: David Mitchell, Metropolitan State University, 494 King Center, Campus Box 32, P.O. Box 173362, Denver, CO 80217, Tel.: 303-352-4114, Email: dmitch58@msudenver.edu
Another goal is to examine the types of social and linguistic attitudes and beliefs that are associated with these perceived dialectal differences. Finally, we address the question of how these folk perceptions of $\mathrm{AAE}$ variation align with those that have been identified in previous studies on American English more generally.

\section{Aae Regional Variation and Perceptual Dialectology}

\subsection{AAE Regional Variation}

Although AAE has been studied quite extensively, it has been noted that until recently the research on it has tended to focus on a rather limited range of research questions and linguistic variables (Winford, 2000; Thomas, 2007; Thomas \& Wassink, 2010). The main research questions have concerned the origins of AAE and its relationship to European American dialects. Variationist studies on AAE have centered primarily on describing a narrow set of morphosyntactic features, and there has been relatively little research focusing on other sociolinguistic topics concerning language use and identity in African American communities (Morgan, 1994; Winford, 2000). One major reason for this state of affairs is that, despite their best intentions to highlight the systematic nature of AAE grammar and to address issues of social inequality and educational access (Labov, 1972; Morgan, 1994; Wolfram, 2007:16; Thomas \& Wassink, 2010:157), sociolinguistic studies have often failed to consider the perspectives of AAE speakers. As Wolfram \& Kohn (2015:141) note, many of the influential early studies of AAE were carried out by 
Northern white linguists who did not have firsthand experience with the diversity of African American communities and their speech varieties. As a result, what constitutes AAE and membership in the speech community has often been defined in a way that reflects dominant stereotypes about African Americans rather than intragroup norms and values (Morgan, 1994).

Wolfram (2007) debunked the set of widely held beliefs that have guided and limited previous research on AAE; this "sociolinguistic folklore" includes the belief that the structure of AAE is uniform across regions (the "supraregional myth"), that it is on a uniform trajectory of change (the "unilateral myth"), and that vernacular AAE is only used by the working class (the "social stratification myth"). The present paper mainly addresses the supraregional myth, but as Wolfram observed, the three are interrelated. The supraregional myth is based on early studies on AAE (e.g., Labov et al., 1968; Wolfram, 1969; Legum et al., 1971) that showed that the speech of African Americans from urban centers across the country shares a set of core morphosyntactic features (e.g., habitual be, copula absence, and inflectional $-s$ absence) as well as certain consonantal features (e.g., postvocalic r-lessness and consonant cluster reduction). This supraregional set of vernacular features was thought to "trump" any regional variation in AAE (Wolfram, 2007:5).

However, regional variation in AAE cannot be ignored (Wolfram, 2007; Wolfram \& Kohn, 2015). Comparing results from several studies done in African American communities across North Carolina (e.g., Wolfram \& Thomas, 2002; Carpenter, 2005; Childs \& Mallinson, 2004, and Rowe 2005, to name just a few), Wolfram (2007:5-9) showed that there is regional and generational variation in the frequency of postvocalic r-lessness and 3SG inflectional $-s$ absence. At a broader regional level, Charity (2007) found differences in the frequency of four morphological features (zero plural, zero possessive $-s$, zero verbal $-s$, and zero copula) and two phonological features (consonant cluster reduction and the realization of interdental fricatives as stops or labiodentals) in the speech of schoolchildren from New Orleans, Louisiana, Washington, DC, and Cleveland, Ohio. These studies show that even if there is a core set of vernacular AAE features, there is still regional variation in terms of their frequency of use in different communities.

Outside of the canonical set of features, there is still much to explore. As Fought (2006:59) observed, European American regional dialects vary much more in terms of phonological features than in morphosyntactic features, so AAE might be expected to vary the same way. Green (2002:1-2, 120-121) also mentioned that regional AAE varieties may share similar syntactic features but differ in terms of their vowels. There also may be more room for variation in the phonology given that many African Americans speak in a style or dialect with few of the vernacular grammatical features, particularly those that are stigmatized, but often retain some AAE phonological features. ${ }^{2}$ Phonetics and phonology have historically received relatively little attention in AAE research, but a growing number of studies in this area have indeed revealed regional variation (see Thomas, 2007; Thomas \& Wassink, 2010; and Wolfram \& Kohn, 2015 for overviews). The lexicon is another area that is likely to show regional variation, although this topic has also received less attention in AAE studies (Thomas, 2007:470).

In terms of phonology, rhoticity is one aspect of AAE that has been documented to vary by region. In general, r-lessness occurs in AAE in postvocalic, unstressed contexts (e.g., brother, forget) and in final and preconsonantal position (e.g., four, hard); less commonly, in parts of the Deep South, it can also occur in stressed syllabic position (e.g., work, stir) (Thomas, 2007: 453-454). However, AAE in Columbus, Ohio (Thomas, 1989) and Davenport, Iowa (Hinton \& Pollock, 2000) is highly rhotic. Hinton \& Pollock (2000) compared the Davenport dialect to the non-rhotic AAE dialect in Memphis, Tennessee; they attributed the regional difference to the convergence of Davenport AAE with the local, rhotic European American dialect and to the participants' negative opinions of Southern, "country" AAE. Other consonantal variations in AAE dialects include the reduction of $/ \mathrm{ks} /$ to $[\mathrm{k}]$, as in box (Fasold \& Wolfram, 1970), and the use of [skr] for /str/ in words such as street [skrit] and strong [skron] (Rickford \& Rickford, 2000:103-104; Green, 2002:122), which both reportedly occur in the South.

Overall, the vowel systems of AAE dialects in different regions are similar enough to speak of an African American Shift (Thomas, 2007:464). However, a number of phonetic studies have focused on describing AAE speakers' convergence to or divergence from local European American dialects in vocalic chain shifts (e.g., Fridland, 2003; Eberhardt, 2008; Yaeger-Dror \& Thomas, 2010; Risdal \& Kohn, 2014), and comparison of results across studies reveals considerable regional variation (Thomas, 2007:460-266; Thomas \& Wassink, 2010:160-162; Wolfram \& Kohn, 2015:148-151). For example, GOAT and GOOSE vowel fronting are not generally characteristic of AAE, but it can be found in regions where it is common in the local European American dialects, such as Columbus (Thomas, 1989; Durian et al., 2010) and Memphis (Fridland \& Bartlett, 2006).

Another example of AAE regional variation is the centralization of front vowels before / $r$ / (i.e., the URR variable). This feature has been documented in the following areas: Memphis; St. Louis, Missouri; East 
St. Louis, Illinois; Prince George's County, Maryland; and Washington, DC (Hinton \& Pollock, 2000; Blake \& Shousterman, 2010). There is also anecdotal evidence that it occurs in Mississippi, Virginia, and Baltimore (Blake \& Shousterman, 2010:243). This centralization results in the merger of here, hair, and her as [h3'] or marry, merry, Mary, and Murray as [m3rri] (Blake \& Shousterman, 2010:231). Green (2002:123) described a similar lowering of the vowel in hair or care in central and northern Texas. This variation in AAE arose independently from the influence of the surrounding European American dialects (Wolfram \& Kohn, 2015:151).

\subsection{AAE and Perceptual Dialectology}

There are few studies involving the phonetic or folk perception of regional AAE varieties. In an ethnic dialect identification experiment, Thomas \& Reaser (2004:77) found that European American and African American listeners both had difficulty identifying the ethnicity of African Americans from Hyde County, North Carolina, whose variety differs from "prototypical" AAE because it shares several phonological features with the local European American vernacular. In perceptual dialectology studies, mentions of African American speech have occasionally been made by participants, but not from the perspectives of African Americans themselves. For example, in a study in southeastern Michigan, a European American man commented that "the regional differences of Black English are closer to each other, than the difference between Black English and Midwest white English", although he recognized that Northern and Southern AAE are different (Niedzielski \& Preston, 2003:129). Campbell-Kibler's (2012:295-297) study on the perceptual dialectology of Ohio found that the European American participants tended to racialize urban areas such as Columbus and Cleveland, describing their speech as ghetto, Ebonics, and black. In a study on California, some participants also referred to African American speech as characteristic of certain cities, in contrast with other dialects and languages found in different parts of the state (Bucholtz et al., 2007). However, variation within AAE has not been the primary focus of any previous perceptual dialectology studies.

There are signs that African American participants would have a lot to say about regional dialects of AAE if researchers asked. Wolfram (2007:18) noted that African Americans interviewed for Voices of North Carolina (Hutcheson, 2005) often made unsolicited comments about AAE variation in different parts of the state, and the Iowa participants in Hinton \& Pollock's (2000) study expressed negative opinions of Southern speech. It is also easy to find these types of discussions taking place in everyday interactions, either in person or online on blogs, Twitter, and YouTube. For example, on its Curious City blog, the Chicago radio station WBEZ91.5 had an informative piece exploring regional "blaccents" (Minoff, 2013). The article featured personal interviews and examples from African American YouTube users who had participated in a popular "accent tag" meme in which people read and comment on a list of words as pronounced in their particular region. Similarly, references to different kinds of AAE accents can be found in hip-hop music. For example, in "Cleveland is the Reason" (2008), Kid Cudi raps about how "the double $\mathrm{O}$ [Ohio] got her own accent," and in "Soldier" (2004), Houston-based Destiny's Child mentions "that East Coast slang that us country girls we like." It is clear that many speakers have high metalinguistic awareness of dialectal variation in AAE, but it has not yet been systematically studied by sociolinguists. The present study aims to describe some of these folk perceptions, centering African Americans' perspectives on the regional variation in their dialects.

\subsection{Previous Findings on the Perceptual Dialectology of American English}

To provide a basis of comparison for the results of this study, we briefly summarize some of the general findings from previous research on the perception of regional variation in American English. First, it should be noted that because many previous American perceptual dialectology studies have been conducted on college campuses, there has been an implicit focus on the perceptions of white, middle class speakers. Preston (1986), Hartley (1999), and Bucholtz et al. (2007), for example, each describe the participants in their studies as all or mostly white. Ethnicity has usually only been mentioned by participants to highlight places that are perceived to deviate from the implicit white norm, such as the perceived "black" speech of urban areas like Cleveland (Campbell-Kibler, 2012:295-297) and Detroit (Niedzielski \& Preston, 2003:59), African-American influence in the South (Fought, 2002:128), or Cajun and Creole speech in Louisiana (Lance, 1999:297).

Previous studies have found variation in how participants from different regions draw and label regional boundaries, depending on where they are from; for example, people from Washington include a much larger number of states in the New England region compared to people from New York (Lance, 1999:286), and Californians (like many other Americans) seem to have a nebulous notion of where exactly the Midwest is (Fought, 2002:119-120). However, the labels used for different regions are fairly consistent across studies, and they are attached to similar cultural and linguistic stereotypes, even if they may not consistently apply to the same sets of states. 
One consistent finding is that the South is the most salient dialectal region in the US, as the speech there is considered highly nonstandard (Niedzielski \& Preston, 2003:57). Comparisons of map tasks done in several states have shown that it is the most frequently identified region (94\% of all participants in Preston, 1986) and has the most consistent set of states included in it (Lance, 1999). The next most frequently used broad regional labels in Preston's (1986:233) study were the Midwest (55\%), the Northeast or New England (49\%), the West (35\%), and the North (33\%). Some specific cities and states were also frequently recognized as dialectal zones: New York City (44\%), Texas (43\%), and California (40\%). Less frequently mentioned areas in the Preston (1986) and Lance (1999) studies include subregions of the South (Appalachia and the Upper South) and West (the Northwest and the Southwest).

Participants in previous studies have also consistently referred to certain widespread American regional stereotypes and language ideologies (e.g., those discussed in Kolker \& Alvarez. 1987; Lippi-Green, 1997). For example, New Yorkers, or East Coast residents more generally, are often described as angry, fast-talking, cold, tough, and rude (Hartley, 1999:327; Fought, 2002:129). In contrast, Southerners are commonly described as slow (in speech or in pace of lifestyle) and unsophisticated ("hicks" or "hillbillies"), but hospitable and friendly (Preston, 1986:231; Hartley, 1999:329; Fought, 2002:128). The West, particularly California, is often described as laid-back, sunny, partying, and having Valley Girl or surfer talk (Preston, 1986:229; Fought, 2002:131; Niedzielski \& Preston, 2003:59). The Midwest, on the other hand, is usually defined by its perceived lack of cultural or linguistic flair in comparison to these other regions; its speech is often described as normal, standard, or having accent-free or "newscaster" speech (Lance, 1999:296; Niedzielski, 2002; Niedzielski \& Preston, 2003:59-61).

In the context of the previous findings, one question is how the perception of regional African American speech and culture fits into these broader American stereotypes. Another is how the perception of AAE dialect boundaries may align with or differ from those identified in previous perception or production-based studies. Production-based dialect maps (e.g., those in Carver, 1987 or Labov et al., 2006) reflect the historical patterns of migration as American settlers expanded from east to west (Wolfram \& Schilling-Estes, 1998: 107-113). While the dialect boundaries described in previous folk perception studies of course do not always match those of documented production (Preston 1986:243), and there is considerable individual variation in how participants draw and label maps, they are often fairly close (Lance, 1999:310-313; Niedzielski \& Preston, 2003:82-95).
However, African American migration has followed different routes. During the Great Migration (approximately 1910-1970), millions of African Americans moved from the South to the North and West (Tolnay, 2003:210-211). Rail and highway connections contributed to the development of steady migration streams between certain regions: Louisiana and Mississippi to Chicago; Georgia and South Carolina to Philadelphia, New York, and Boston; and later, Oklahoma, Texas, Louisiana, and Arkansas to California (Tolnay 2003:217). Many migrants have maintained family connections to the South. Thus, one prediction of this study is that African American participants might divide and label their maps in ways that reflect these historical links between regions.

\section{Methods}

\subsection{Fieldwork}

Fifty-five participants were recruited from neighborhoods around east, west, and central Columbus. The neighborhoods selected were predominantly African American and working class. Participants were approached while walking down the street, sitting on the porch of their homes, and in a barbershop on the east side of town. The fieldworker (the first author) was a 34-year-old African-American man and northern Ohio native who dressed casually. Throughout the task, he did his best to reflect the speech of all participants; for example, when participants showed traces of AAE in their phonology only (e.g., word-final consonant deletion), he only used phonological markers of AAE in his own speech. When participants showed signs of AAE morphology (e.g., lack of third singular $-s$ ) and syntax (e.g., lack of do-support), the fieldworker also incorporated these features into his own speech. Since he was not introducing features they were not already using, we do not think this biased participants, and the primary purpose of this codeswitching was to make participants feel comfortable.

The age range of the participants was 21 to 72 years old $($ mean $=33$, median $=30$ ). There were 20 participants who identified as female and 35 as male. With regard to ethnicity, 48 participants identified as black, 3 as black/multiracial, and 4 as belonging to another group (e.g., Hispanic, "Italian/white"). Participants were asked to rate their familiarity with Black English/ African American English on a scale ranging from 1 to 6 , which resulted in a mean rating of $5.47 .^{3}$ Twentynine of the participants were originally from Ohio. Five were born elsewhere in the North, 13 were native to the South, 7 were from the New York City/New Jersey area, and 1 was from the Southwest. Additionally, many of the participants had lived in multiple states in different regions, which was reflected in participants' 
comments that African Americans in Ohio are highly mobile (see Section 4.3.4).

Participants were approached and asked if they would be willing to take a map survey about language, for which they were to be compensated $\$ 5$. They were told that the survey deals with the different ways in which African-Americans speak casually, "in the street" when talking to each other, and that all they needed to do was to write down any differences that they themselves have noticed in any part of the country. They were given the option to identify these differences, using circles and/or dividing lines, in order to section off any areas where they felt black speech to be unique or to have peculiar linguistic features. Moreover, they were given the freedom to circle entire sections or individual states, as well as add individual cities. Participants were instructed to write down examples of linguistic features anywhere on the map, as long as it was possible to identify the area to which they were referring. The most common technique they used can be seen in Figure 2, where the participant circled familiar areas and drew an arrow from those circles to the relevant commentary in the margins. Occasionally, the fieldworker added phonetic transcriptions to clarify some of the examples or comments (which we have marked in square brackets in the analyses below).

\subsection{Data Analysis}

We coded each map for the ways in which participants had grouped states together, as well as the social and linguistic stereotypes and values they attributed to black speech from those regions, including any mentions of specific linguistic features. To analyze how participants grouped states together, ${ }^{4}$ we created a dissimilarity matrix based on which other states a state was grouped with using the $\operatorname{dist}()$ function in $\mathrm{R}_{,}^{5}$ and performed a hierarchical cluster analysis using the hclust() function. For our investigation of linguistic and social stereotypes and attitudes, we counted how often a feature or term was used to describe language in a state (on its own, or as part of a larger grouping).

Interpreting participants' intentions based on their maps was not always easy. For example, if they drew a big circle centered on Texas, did they intentionally include Oklahoma and New Mexico? Did comments beside a Southern state refer to that state specifically, or a larger region? If participants wrote a word with non-standard orthography, were they highlighting lexical variation, or differences in pronunciation? In our analysis, we took a conservative approach in a number of ways. First, each map was coded independently by two authors, and any disagreements in boundaries or comment-place attributions were decided by a third author. Second, we tried to code objectively based on the maps, and not the suspected intentions of our participants: if half or more of a state was included in a circle, we included it in the grouping. Third, in the analyses of lexical and phonological variation below, we explicitly acknowledge the ambiguous meaning of certain participant comments.

The other important thing to note about the analyses is that they generally function at the unit of the state. The maps given to the participants had state boundaries, and most participants divided their maps at the state level. However, there were times that participants noted within-state variation, most notably by dividing Northern and Southern California and the three dialect regions of Ohio. Additionally, participants often commented on variation at the city level, although no cities were marked on the original maps. Cincinnati, Columbus, Cleveland, Chicago, New York City, Los Angeles, San Francisco, Houston, St. Louis, New Orleans, Baton Rouge, Atlanta, Philadelphia, and Miami were cities that were singled out. For ease of analysis, in the graphs below, such sub-state commentary is applied to the whole state.

Finally, while Alaska and Hawaii were included on the map participants received, each state received only three comments (from a total of three participants), and these were primarily to express that they had nothing to say about African American English in these states (e.g., not sure how their English is spoken, proper or slang $\left.(\# 5, \mathrm{AK})^{6}\right)$. For this reason, these states are not included in any mapping of features below.

\section{Results}

In the results that follow, it is clear that while the broad dialect groupings and attitudinal stereotypes generally match patterns seen in other perceptual dialectology studies of American English (e.g., Preston, 1986; Lance, 1999; Niedzielski \& Preston, 2003), participants offered commentary and linguistic examples that were specifically related to African American English and show an awareness of variation in AAE across the US.

\subsection{State Groupings}

Table 1 shows the broad regional labels used by participants, and the states they applied the terms to.

To investigate more thoroughly how participants grouped states together, we plotted a dendrogram based on a hierarchical cluster analysis. As visible in Figure 1, the clustering analysis suggests a primary split between the South and everywhere else. The South then splits into the Deep South (Georgia, Alabama, South Carolina, and Mississippi, plus Tennessee and North Carolina) and Florida on the one hand, and Louisiana, 
Table 1. Participant labels for supra-state regions. Bracketed numbers indicate that the label was attributed to that state more than once.

\begin{tabular}{|c|c|c|}
\hline Label & Count & States Included \\
\hline Deep South & 1 & $\mathrm{FL}, \mathrm{SC}, \mathrm{AL}, \mathrm{GA}, \mathrm{NC}, \mathrm{MS}$ \\
\hline South & 5 & $\begin{array}{l}\mathrm{AL}(3), \mathrm{AR}(4), \mathrm{GA}(4), \mathrm{LA}(5), \mathrm{MS}(3), \mathrm{MO}, \mathrm{NC}(2), \mathrm{SC}(3), \mathrm{TX}(3), \mathrm{VA}, \mathrm{FL}(3) \text {, } \\
\mathrm{TN}(3), \mathrm{OK}(2) \mathrm{OH}, \mathrm{IN}, \mathrm{KY}, \mathrm{WV}, \mathrm{VA}\end{array}$ \\
\hline East & 1 & DE, MD, NJ, NYC, PA \\
\hline East Coast & 6 & $\begin{array}{l}\mathrm{CT}(4), \mathrm{DE}(5), \mathrm{NH}(3), \mathrm{NJ}(5), \mathrm{NY}(4), \mathrm{MA}(4), \mathrm{MD}(5), \mathrm{RI}(4), \mathrm{NC}, \mathrm{PA}(4), \mathrm{VA}(2), \\
\text { WV (2), VT (4), ME (2) }\end{array}$ \\
\hline Midwest & 4 & $\begin{array}{l}\text { IA (2), IL (3), IN (3), MI (3), MN (2), OH (3), WI, KY (2), WI, TX, LA, OK, KS, NE, } \\
\text { SD, ND, MO, AR }\end{array}$ \\
\hline Northeast & 1 & NYC, NJ, CT, RI, MA, VT, NH \\
\hline North/Northern & 2 & IL, IN, MI, OH (2), WV, VA, PA, NJ, NY, RI, CT, NH, VT, MA, RI, ME, KY \\
\hline West & 1 & CA \\
\hline West Coast & 2 & AZ, CA (2), CO, ID, MT, NM, NV (2), OR (2), UT, WA, WY \\
\hline
\end{tabular}

Texas, Oklahoma, and Arkansas on the other. The nonSouth group splits into the West and the North/ Northeast, which splits into the Midwest/Upper South (notably including Kentucky, West Virginia, and Virginia) and the East Coast. These results echo Preston's (1986) finding that the South is the most commonly identified region of the US. However, while he found that Kentucky and Virginia were usually grouped with the South, our results match some of the findings in Lance (1999), who found that they were often grouped with the Northeast or as their own distinct region.

\subsection{Linguistic Features}

\subsubsection{Lexical Differences}

Participants often cited lexical items as being regionally varied in $\mathrm{AAE}$, and the clearest regional patterns were visible in terms of address or endearment, which were either given as examples on their own or included in greetings (see below). The predominance of such terms is consistent with Green's (2002:28-29) observations that terms referring to people make up one of the largest categories of AAE slang, and that these terms vary regionally. We plotted the distribution of the three most commonly identified terms of address: shorty (Map 1), which was predominant in the Deep South (with some phonological variation), especially in Georgia; son/sun (Map 2), listed almost exclusively in the Northeast, especially in New York; and bro ${ }^{7}$ (Map 3), attributed almost exclusively to Ohio, particularly the central region. The term baby/babay was also mentioned twice (FL/LA), as were god (NY) and $y^{\prime}$ all (AL, AR, FL (2), GA (2), KY, LA (2), MS, NC, SC, TN (2), VA, WV). The terms $B$ (MD, NY, NJ, PA), kid (PA), my nigga $(\mathrm{OH})$, homie (Cleveland), bruh (KY), patna (KY), and young bull (PA, NJ, MD, DE) were each mentioned once.
Greetings were also mentioned frequently, but often in combination with terms of address (i.e., What up B?), so it was not clear whether the participant was highlighting the greeting form or the term of address. We plotted the distribution of the most commonly mentioned greeting (yo) in Map 4; the term was exclusively connected to Northern states, particularly around New York City. Regional patterns were less clear in other greeting constructions, which we have included in Table 2. The predominance of greetings in the map labels, along with terms of address, reflects the cultural and pragmatic importance of this speech act in AAE. For example, their variety and cultural significance was celebrated in a popular Twitter hashtag, \#BlackMenGreetings, which included many of the greeting and address forms mentioned in this study (e.g., what's good baby and waddup God; see Blavity 2016).

The other most common lexical item was word, mentioned by 3 participants in 4 constructions (1-3), and exclusively attributed to the urban Mid-Atlantic area. For interest, we have included other lexical items (mostly mentioned just once) in Table 3.

(1) word; word is born (\#5, circling CT, DE, MA, MD, NJ, NY, PA, RI, VT-south)

(2) word is bond (\#43, NYC, NJ)

(3) word to ya motha (\#57, Philadelphia)

\subsubsection{Phonological Features}

Non-rhoticity was mentioned 9 times by 5 participants. The comments we coded as referring to non-rhoticity were either explicit descriptions (does not pronounce "R"s, \#3), less explicit descriptions (emphasis on Os, less on the Rs, \#504), or specific examples (floor $>$ flo, door $>$ doo, \#57). Map 5 shows that the participants most commonly described the Southern regions as non-rhotic, ${ }^{8}$ and never the West or New England. 


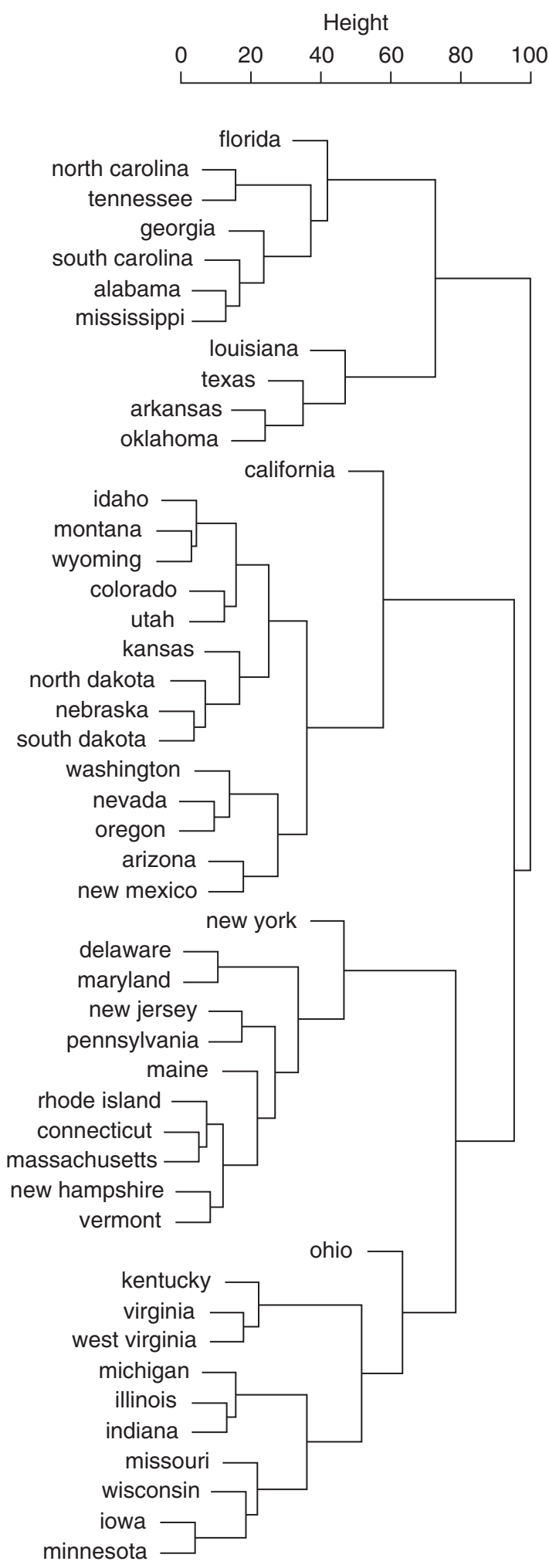

Figure 1. Dendrogram showing the hierarchical clustering of states across participants.

We have one example of a participant saying emphasis on Rs (\#504) while pointing to Alabama, which may indicate that the participant thought rhoticity was a

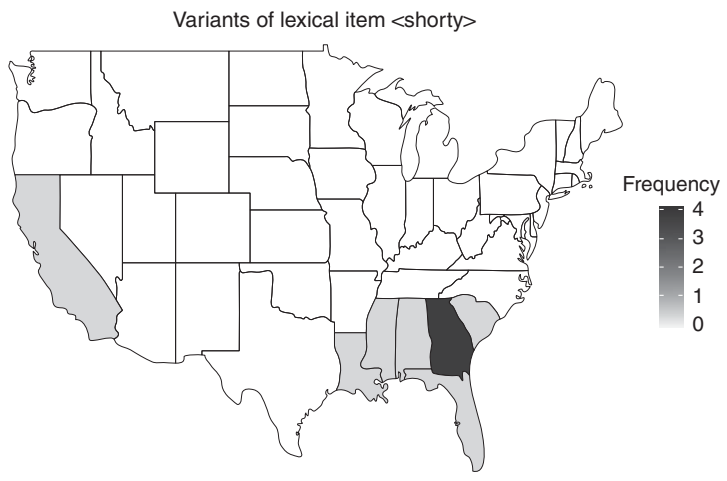

Map 1. Distribution of the lexical item "shorty" by state. Variants include "shorty," "shawty," and "shoddy".

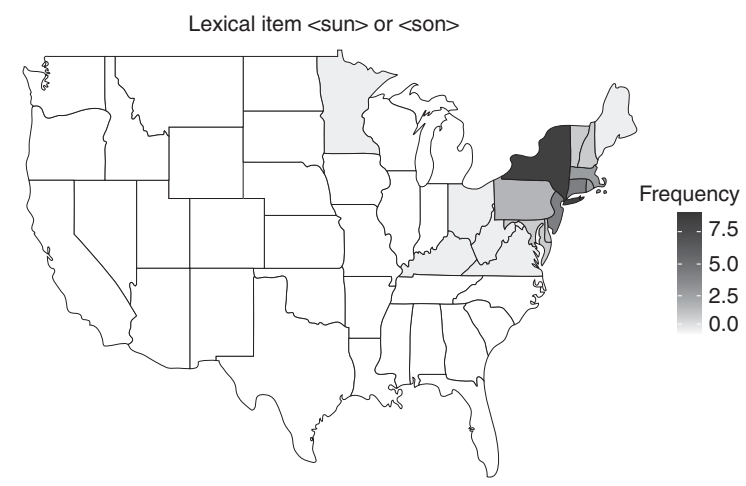

Map 2. Distribution of the lexical item "sun" /"son" by state.

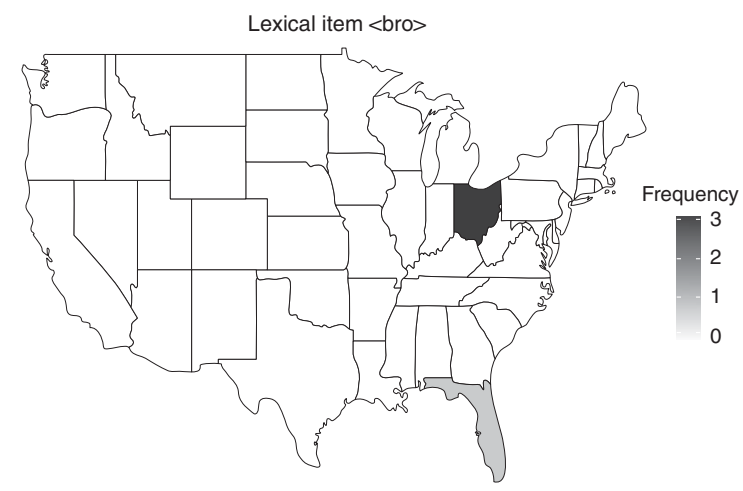

Map 3. Distribution of the lexical item "bro" by state.

feature of that area, but it could also refer to another variable, such as URR.

We coded five comments as referring to the URR variable. Of the four that referred to Southern areas, two of these were incontestably about URR $(4,5)$, while two were likely so $(6,7)$. The fifth $(8)$, used about the East Coast, is another possible mention of URR; the variable has previously been documented in the AAE of Maryland and possibly Virginia (Blake \& Shousterman, 2010).

(4) Here is pronounced her (\#54, MO, OK, KS, AR-north, IA, IL) 
(5) Here vs. Hurr (\#23, TX)

(6) a lot of "er" sound (\#1, AL, AR, GA, LA, MS, MO, $\mathrm{NC}, \mathrm{SC}, \mathrm{TN}, \mathrm{TX}, \mathrm{VA})$

(7) beer - ber (\#502, FL, SC, AL, GA, NC)

(8) Mary = Murry (\#513, VA-north, NJ, DE, MD) SKR was unambiguously mentioned by four participants, and it was restricted to the South (9-12).

(9) they say -street- -screet- (\#16, TX)

(10) Don't pronounce correctly... shrimp, scrimp (\#18, GA)

(11) They say stuff like scrating out the rag or skreet (\#55, MS)

(12) Street would sound like shkreet (\#504, TX, SC, AL, MS, GA)

A few other phonological variables that have been attested in the literature were also mentioned by participants: final consonant deletion $(13,14)$, /au/monophthongization $(15,16)$, and TH-stopping (17-19).

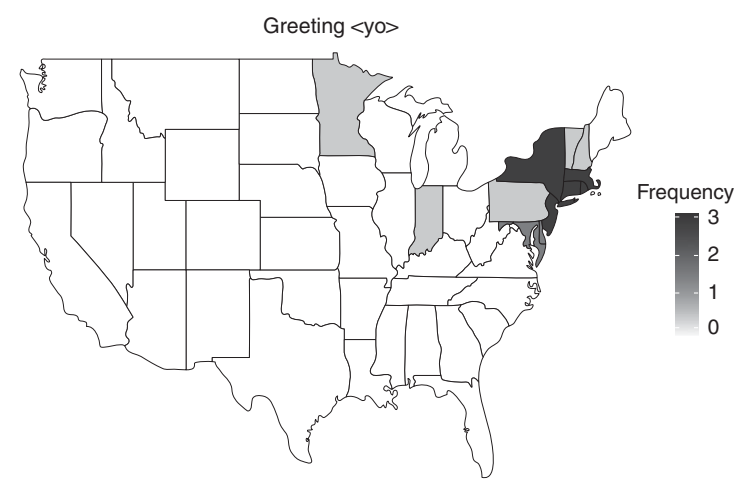

Map 4. Distribution of the greeting "yo" by state.
(13) those [thou], (\#45, LA)

(14) wha instead of what (\#516, NY, NJ, PA, CT)

(15) now is nah (\#54, MO, OK, KS, AR-north, IA, IL)

(16) H-tahn (\#511, Houston)

(17) dat (\#46, LA, FL, GA, TN)

(18) what up doe (\#32, MI)

(19) whodat (\#24, LA, MS)

\subsubsection{Morphosyntax}

Morphosyntactic features were rarely mentioned by the participants. The exception was (FIXING), which was mentioned by four participants and usually attributed to speakers in the South. There is some phonological variation in the (FIXING) comments; for example, participant \#5 attributed finnin to the South in (20), while participant \#54 wrote fittin and circled Western states in (21). Example (20) was also accompanied by a mention of gon, another future marker.

(20) finnin (\#5, AL, AR, FL, GA, KY, LA, MS, NC, $\mathrm{SC}, \mathrm{TN}, \mathrm{VA}, \mathrm{WV}$ )

(21) They say fittin for about to (\#54, CA, NV, UT, CO, NM, AZ)

(22) "fin to fix" instead of getting ready to (\#56, AR)

(23) finna go to the store (\#519, AR)

\subsection{Social Evaluations of the Dialects}

The following subsections focus on the social and evaluative commentary made about speech styles in different regions. However, as has been found in many other studies of perceptual dialectology and language

Table 2. Greetings (hellos and goodbyes) by state. Bracketed numbers indicate that the greeting was attributed to that state more than once.

\begin{tabular}{|c|c|c|}
\hline Greeting Form & Other Variants & States Included \\
\hline dueces! ('deuces') & & IN, IL, KY, MI, OH, WI \\
\hline $\mathrm{Hey}$ & & FL \\
\hline How u doin! & how you doing & $\begin{array}{l}\text { CT, DE, MA, MD, ME, A, IL, IN, MI, MN, OH, WI, NH, } \\
\text { NJ, NY, PA, RI, VA, VT, WV }\end{array}$ \\
\hline Howdy & & AR, LA, OK, TX \\
\hline outty & & IN, IL, KY, MI, OH, WI \\
\hline wat yo name be & & $\mathrm{AL}, \mathrm{AR}, \mathrm{FL}, \mathrm{GA}, \mathrm{KY}, \mathrm{LA}, \mathrm{MS}, \mathrm{NC}, \mathrm{SC}, \mathrm{TN}, \mathrm{VA}, \mathrm{WV}$ \\
\hline what good & what's good & IN, IL, KY, MI, OH, WI, TX \\
\hline what it do & & IA, IL, IN, MI, MN, OH (2), WI \\
\hline What it is? & & IN \\
\hline what the lick read & & FL \\
\hline what up & $\begin{array}{l}\text { wasup; sup; what up with it; } \\
\text { whaddup, what up doe }\end{array}$ & $\begin{array}{l}\mathrm{AL}, \mathrm{FL}, \mathrm{GA}, \mathrm{MS}, \mathrm{SC}, \mathrm{IA}, \mathrm{IL}, \mathrm{IN}, \mathrm{MI}(2), \mathrm{MN}, \mathrm{WI}, \mathrm{OH}(2), \\
\text { NY (3), PA, NJ, MD, FL, }\end{array}$ \\
\hline what's poppin & & $\mathrm{AZ}, \mathrm{CA}, \mathrm{CO}, \mathrm{ID}, \mathrm{MT}, \mathrm{NM}, \mathrm{NV}, \mathrm{OR}, \mathrm{UT}, \mathrm{WA}, \mathrm{WY}$ \\
\hline Where you going? & & NY \\
\hline Whodat & & LA, MS \\
\hline
\end{tabular}


Table 3. Other lexical items by state or city. Asterisks mark definitions written by the participants themselves on their maps. The ${ }^{+}$sign marks entries where it was unclear which term was being attributed to that location. Bracketed numbers indicate that the greeting was attributed to that state more than once.

\begin{tabular}{|c|c|c|}
\hline Item & Meaning & States or cities \\
\hline all ready & 'okay'* & GA \\
\hline beat to go down the way & $\begin{array}{l}\text { 'about to go to a place (that is known to } \\
\text { both parties)' }\end{array}$ & Philadelphia \\
\hline edge up & 'haircut'* & $\mathrm{OH}$ central \\
\hline fasho & 'for sure' & OR, CA, NV \\
\hline feel me & tag question & WA \\
\hline "flappin" = "cappin" & 'shooting'* & CA \\
\hline for shizzel my nizzel & 'for sure my nigga' & CA-north \\
\hline gym shoes vs. sneakers $^{+}$ & & NY \\
\hline hella & intensifier & AZ, CA (3), ID, NV, OR, UT \\
\hline huck-a-buck & a sexual position & MS \\
\hline " $i$ " (at end of phonecalls) & possibly a reduced form of 'alright' & $\begin{array}{l}\text { OH, WV, VA, PA, NJ, NY, RI, CT, NH, } \\
\text { VT, MA, RI, ME, KY }\end{array}$ \\
\hline jawn & generic pronoun & Philadelphia \\
\hline juke & 'dance'* & IL-north \\
\hline line up & 'haircut'* & OH north \\
\hline pop & 'carbonated beverage' & $\mathrm{OH}(2)$ \\
\hline pop off & 'begin violently' (e.g., a fight) & $\begin{array}{l}\text { CT, DE, MA, MD, NJ, NY, PA, RI, VT- } \\
\text { south }\end{array}$ \\
\hline riding & 'joking'* & $\mathrm{OH}$ north \\
\hline riffin & 'joking'* & $\mathrm{OH}$ central \\
\hline rump & 'butt'* & MS \\
\hline scoop, whip, dip, slide & 'leave'* & $\mathrm{AL}$ \\
\hline slut vs. bop ${ }^{+}$ & 'a promiscuous woman' & $\mathrm{OH}$ \\
\hline soda & 'carbonated beverage' & VA, NC, SC, AL, GA, FL-north, LA, MS \\
\hline soda vs. pop ${ }^{+}$ & 'carbonated beverage' & $\begin{array}{l}\text { ME, NH, VT, CT, MA, NY, NJ, MD, DE, } \\
\text { RI, PA }\end{array}$ \\
\hline stick & 'AK47, AR-15'* (gun) & Miami \\
\hline vicious & 'combative, dangerous' & $\mathrm{OH}$ \\
\hline yonder & 'over there' & TX, MS \\
\hline
\end{tabular}

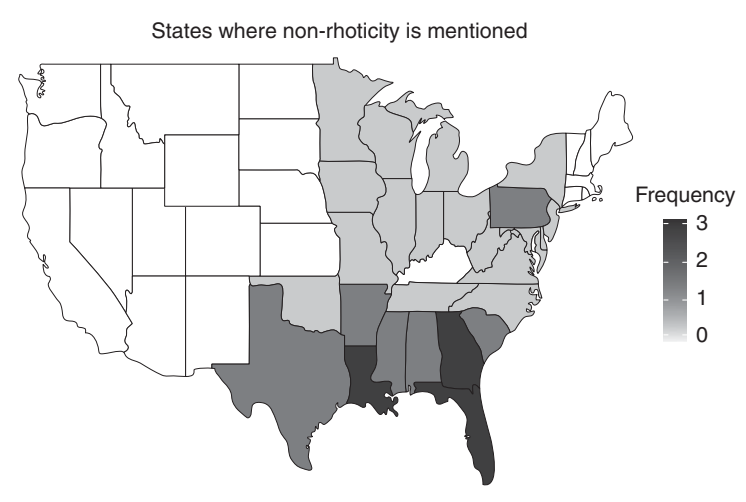

Map 5. Distribution of comments about non-rhoticity by state.

attitudes (Preston, 1986:229; Preston, 2002:69, 75-76), the comments we elicited about regional dialects were often ambiguous in whether they referred to the speech or to the speakers themselves (e.g., fast, slow, aggressive), and some comments were unambiguously only about speakers (e.g., gangs, wear hats), pop cultural references (e.g., The Wire), or even the environment (e.g., hot, area is filthy). In the following paragraphs, we outline common themes in such commentary.

\subsection{1 "Proper" vs. "Broken" English}

As is common in discussions of white varieties of American English, one of the biggest distinctions that participants made on their maps was where the best and the worst English is spoken. Map 6 shows the number of times the term "proper" was used to describe the speech in a state, either on its own, or grouped with other states. Note that this analysis does not include synonyms like "norm(al)" $(\mathrm{N}=5)$, "regular" $(\mathrm{N}=1)$, "standard" $(\mathrm{N}=1)$, "average" $(\mathrm{N}=1)$, "correct" $(\mathrm{N}=0)$, "well-spoken" $(\mathrm{N}=1)$, "understandable" $(\mathrm{N}=1)$, or "clear $(\mathrm{ly})$ " $(\mathrm{N}=2)$. The dominance of the specific term "proper" here (which was used 24 times by 19 participants) suggests an enregistered African American-specific concept of "proper English" (see also 
States where speech is called proper

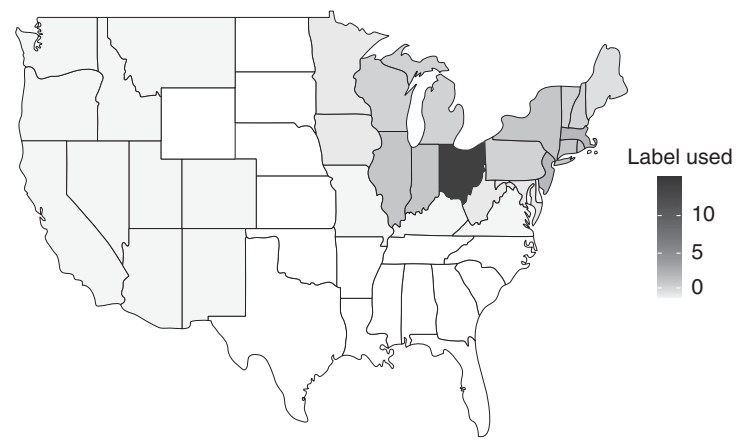

Map 6. Distribution of the term "proper" to describe speech, by state.

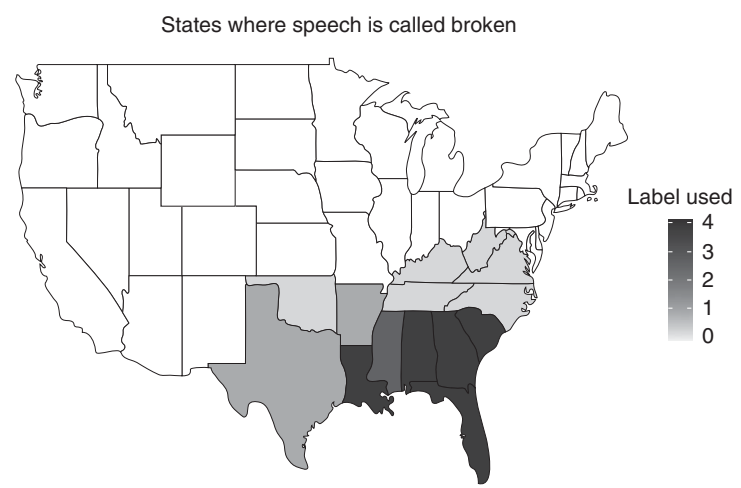

Map 7. Distribution of the term "broken" to describe speech, by state.

Ogbu, 1999; Weldon, 2015). The maps show that Ohio, and the North in general, was identified as the center of proper speech. This finding indicates some linguistic security on the part of the participants, who mostly came from this region. While the West Coast is also occasionally called "proper," there were no instances of participants labeling Southern speech as such. Southern speech, conversely, was the only regional variety labeled "broken" (Map 7), reflecting common American stereotypes about the region.

\subsubsection{Comments about ethnicity}

Seven comments referenced white English. One of these, in (24), was to emphasize that black speakers in the region sounded different from white speakers:

(24) Southern drawl, but different from "white country" accent (\#513, MS, AL, GA, SC, NC, TN)

However, most of the comments were describing the black speakers in the area as sounding white (25-28).

(25) Blacks are watered down. People are more white sounding (\#54, UT, CO, NM, AZ)
(26) Blend in with white dialect (\#35, WA, OR, $\mathrm{CA}, \mathrm{NV})$

(27) Very hard to tell whether I am speaking to someone African American. They sound like white males. (\#56, OH)

(28) The four people that I have known from Alaska sounded white (\#54, AK)

Two participants specified that when they had used the term "proper," they had meant"white" (29-30):

(29) proper (white basically) $(\# 43, \mathrm{OH})$

(30) proper (white) (\#507, MA)

Without commentary from the other participants who used the word "proper," we cannot know if they were also using it to indicate that black speakers sounded white in these areas, or if they were using it to refer to a standard within AAE (i.e., Standard Black English; Spears, 1988; Rahmann, 2008). However, we do have at least one clear instance of a participant using the words "proper" and "white" on different areas of the same map, indicating that the terms do not necessarily overlap for all speakers (e.g., participant \#35, Figure 2). This finding matches work by Weldon (2015), who finds that people will use the term "proper" to describe standard AAE speakers who are also rated highly for sounding black, as well as for African Americans who "sound white." In addition, while black speech in Ohio was commonly labeled "proper" (see Map 6), it was called "white" only twice: once by a black participant from the South (\#43, comment 29), and once by a Hispanic participant from Cleveland (\#56, comment 27). Black participants originally from Ohio or the North did not label their own "proper" speech as "white."

Participant \#56 (who identified as Hispanic and highly familiar with AAE) consistently appealed to blackness in their labeling, with the implication that a black variety was stronger when a speaker's ethnicity could be identified from their voice alone (31-33):

(31) sound very black (\#56, GA)

(32) sound very black you can def tell they are black (\#56, CA)

(33) sound black, some you wouldn't know (\#56, FL)

Participants also mentioned influences in some regions from other linguistic or ethnic groups. The most common was Spanish, as shown in Map 8. Spanish influence was noted not only in the Southwest and Florida, as in previous studies (Preston, 1986:229; Lance, 1999:307; Fought, 2002:116, 131), but also in the Northeast, which also has large Spanish-speaking populations (including many Afro-Latinos of Caribbean descent). "Islander" influence on speech was mentioned by one participant for Florida and one for Louisiana, and a third 


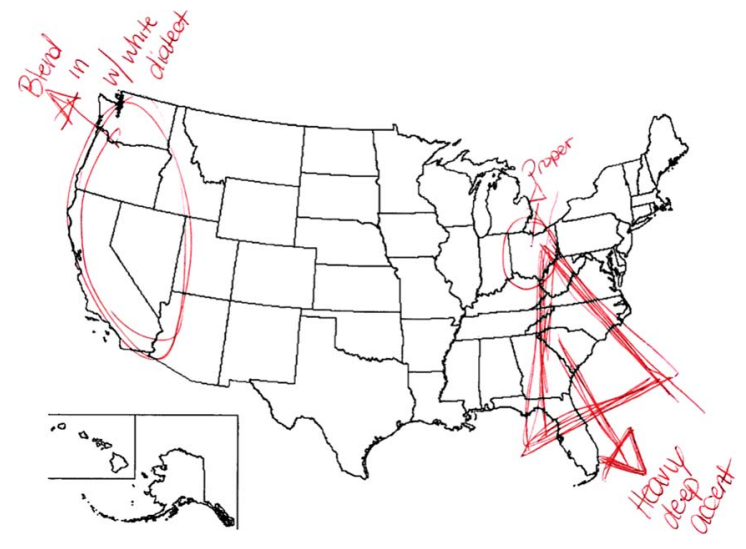

Figure 2. Map of participant \#35. The participant uses the terms "proper" and "white" separately.

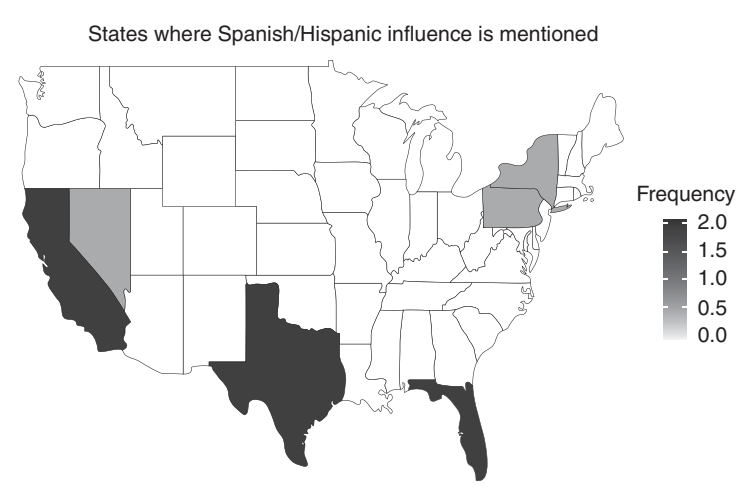

Map 8. Distribution of comments referencing Spanish or Hispanic speech.

participant said that both states have "a Haitian gangster sound mixed with a Midwestern slang" (\#504). "French" was mentioned twice, in reference to LA, GA, $\mathrm{AL}$, and MS as a group, and also to MS on its own. The word "Cajun" was also used to describe LA and MS. One participant (\#513) wrote "Geechie" (Geechee/ Gullah) next to South Carolina. Finally, a description of Philadelphia stated that the speech there sounds "like NY (kind of like Italian)" (\#54).

\subsection{3 "Country" and "South"}

The terms "country" and "South(ern)" were also frequently used by the participants and were not simply applied to Southern states, though they certainly received these labels most often. As Map 9 shows, the term "South(ern)" was used to describe all areas except New England at least once, and it was relatively frequent for Ohio and the surrounding states. The "country" map (Map 10) shares some similarities with the "Southern" map, though the term is applied less often and skips "proper" (yet also "Southern" sounding) Ohio.

African American English is often defined by Southern features, so the participants' perceptions are

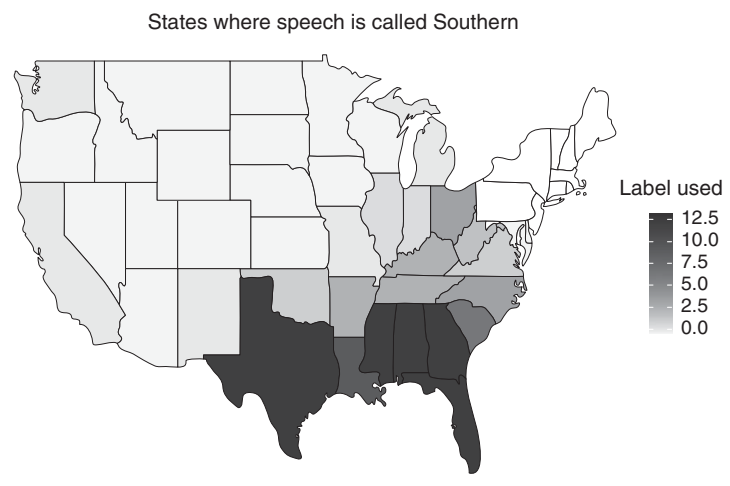

Map 9. Distribution of the term "South" or "Southern" to describe speech, by state.

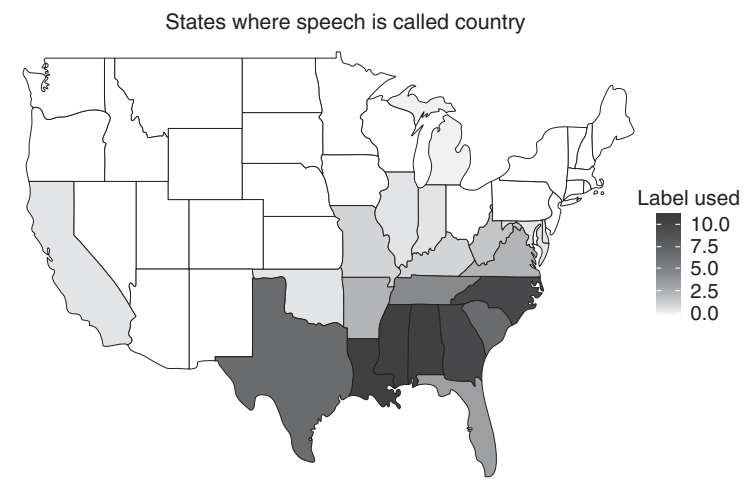

Map 10. Distribution of the term "country" to describe speech, by state.

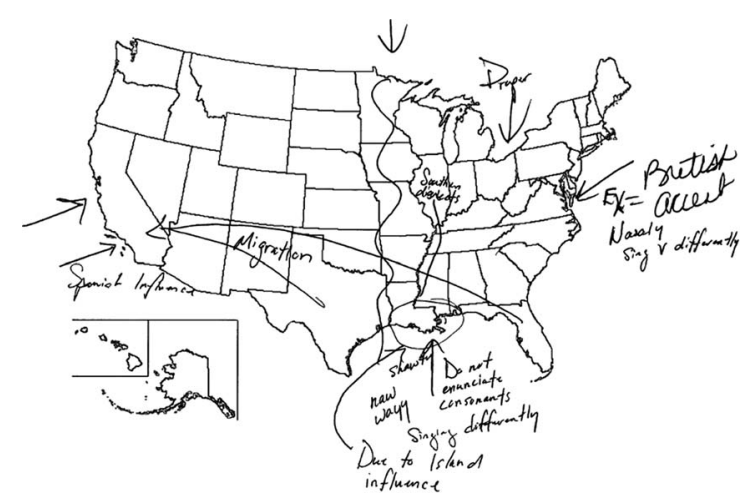

Figure 3. Participant \#19's map, which explicitly references the Great Migration.

accurate in this sense. Maps 9 and 10 both seem to match the patterns of the Great Migration. In fact, one participant marked the Great Migration on her map (Figure 3), and during the task it was common for participants to refer to relatives who still lived down South or had moved from there to the North or West.

\subsubsection{Cultural stereotypes}

The Southern states were labeled hospitable, laid back, and slow more than once, and the latter attribute was 
explicitly connected to the hotter weather there by one participant. The Southern states were also the only areas where people commented (always positively) on food. Other comments of note were that New Orleans is a "party city" (\#136), that TN, GA, AL, and SC are "funny" and use "foul language" (\#51), and that the South "is an area that has an educated population of negros" who are "well spoken" (\#54).

The predominant theme of comments about the East Coast, centered on NYC and Philadelphia, was that people there are rude, disrespectful, aggressive, and mean. The words street and gangs (bloods) were also used to describe the area. The one off-theme comment came from participant \#47, who called NY "upbeat."

Comments about the West Coast centered on California. Cool and laid back were the most common terms used to describe the state and surrounding areas. Diversity and "cultural understanding" (\#47) were also highlighted, as well as stereotypes related to gangs (including comments about gangsta talk and gang slang). Two participants described California with the phrases fast life/fast-paced (\#63,\#15), which could be related to other common descriptions of California as a party state, as in (34).

(34) party state (smoking, drinking) "west coast," "animated," "hyped" (\#46, CA)

There were also some distinctions made within California. One participant described San Francisco as ritzy, in contrast with Los Angeles as ghetto (\#42). Following up on his animated and hyped comments in (34), participant \#46 described the Bay Area as follows:

(35) smurfish, baby-ish, like cartoon characters (\#46, the Bay Area)

The comments in $(34,35)$ are related to the hyphy or "hyperactive" style of rapping, dancing, and partying that is found in the Bay Area (e.g., music by E-40 and Keak da Sneak). Another participant also circled the entire West Coast and labeled it with the terms hyfe (hyphy) and animated Black English (\#18). These comments show that at least in his case, the term hyphy can extend to speech as well as music.

In comments that matched the diverse backgrounds of the participants, it was noted that the Ohio AfricanAmerican community is very mobile (36-41). Some participants suggested that this cultural mixing has had linguistic results $(39,41,42)$, and that the Midwest is moving more towards East Coast pronunciation (43). The multiculturalism of Florida was also mentioned by a few participants.

(36) always from somewhere else $(\# 46, \mathrm{OH})$

(37) cultural diversity $(\# 47, \mathrm{OH})$
(38) little mixed culture $(\# 42, \mathrm{OH})$

(39) Melting pot of different people from wide range of the U.S. Wide range of accents. $(\# 518, \mathrm{OH})$

(40) It's more of a mixture of all like a melting pot. (\#15, IN, IL, KY, MI, OH, WI)

(41) melting pot of language (east west north south) $(\# 52, \mathrm{OH})$

(42) weird New York/California blend (\#513, IL, IN, MI, $\mathrm{OH}, \mathrm{KY})$

(43) I believe the Midwest is becoming more similar to the East Coast - More proper Englishy (\#5, IA, IL, IN, $\mathrm{MI}, \mathrm{MN}, \mathrm{OH}, \mathrm{WI})$

Alongside linguistic comments and examples, participant \#2 consistently used clothing and car styles to describe different regions, as the comments in (44-48) show. The phrases player style and playerish were used to describe California and Ohio by him and another participant. Both made explicit connections between the two states $(44,49)$.

(44) gator shoes, mink coats, major fashion, player style, similar vibe (to $\mathrm{CA})(\# 2, \mathrm{OH})$

(45) lowriders, dixies, braids (\#2, CA-south, AZ)

(46) New Balance, Tim boots (\#2, CT, DE, NH-south, NJ, NYC, MA, MD, RI)

(47) gold teeth, dreadlocks (\#2, AL, FL, GA, MS, SC)

(48) ole school Cadillacs with bullhorn on the front (\#2, OK, TX)

(49) playerish, connection with $\mathrm{CA}(\# 3, \mathrm{OH})$

Participants also characterized different places using cultural references. For example, Florida was associated with Zora Neale Hurston's Their Eyes Were Watching God, and parts of the South (NC, VA, WV, KY, TN) with Alice Walker's The Color Purple. The TV series The Wire, which is set in Baltimore, was mentioned for Maryland. Several states were also labeled with representative rappers, including California (Snoop Dogg, Ice Cube, and Too Short), Ohio (Bow Wow), Florida (Trick Daddy), Georgia (T.I.), and Louisiana (Lil Wayne). To describe the speech of Chicago, one participant mentioned musicians Kanye West and R. Kelly, but as noncanonical (or perhaps just different) speakers from the area (50). The use of the term "proper" in (50) seems to imply not sounding Southern. This participant also drew a line connecting Chicago to Mississippi.

(50) Sound like Mississippi, Kanye and R Kelly sound proper but guy I know from Chi Town sounds Southern (\#57, Chicago)

\section{Discussion and Conclusion}

Previous research on AAE has emphasized the uniformity of the dialect, but the participants in this study recognized clear regional differences, especially in 
terms of phonological and lexical features. In sharp contrast with the primary foci of past AAE research, the participants showed little metalinguistic awareness of morphological features. Work on AAE falls partly within the creolist tradition, where there has been a similar mismatch between what speakers notice and what linguists notice about language (Lesho \& Sippola, 2014). The focus on AAE and creole morphosyntactic features is related to linguists' efforts to explain the origins of these stigmatized language varieties, and how they differ grammatically from the lexifier or standard language varieties.

However, the findings of the present study are in line with those of Ogbu (1999:160), in which African American participants consistently described the differences between white and black English in terms of "vocabulary, accent, and attitudes" (i.e., cultural communication norms or style). Creole folk perception studies have similarly found that speakers are very aware of lexical and phonological variation (Winford, 1976; Wassink, 1999; Irvine, 2004:65-69; Lesho \& Sippola, 2014), or "accent" more broadly (e.g., vague references to "slang," "tone," "singing" speech, etc.). This finding seems to be common across languages in general (e.g., Daan, 1999:19-20; Long, 1999:213; Fought, 2002: 128-131; Kuiper, 1999:257-261; Preston, 2002:58-60; Suárez Büdenbender, 2011).

There were similar patterns to previous perceptual dialectology studies on American English in how the participants recognized dialectal regions and attributed linguistic and social stereotypes to them. It was no surprise that Ohioans considered their own speech normal or "proper" while describing Southerners as hospitable, laid back, and slow, people in the East Coast as rude and aggressive, and Californians as cool and laid back. However, the linguistic examples and social stereotypes associated with these areas were clearly specific to regional African American culture. For example, the cool "party" image of California is manifested in a way that is distinct from the white "surfer" and "valley girl" stereotypes of that region.

The participants' folk perceptions were consistent with findings from production studies in many ways. Lexical differences showed close attention to terms of address, which is a very productive category for AAE slang (Green, 2002:28-29). Non-rhoticity was also a point of focus for many participants, and the states they most frequently identified as being non-rhotic were Southern, which is consistent with documented regional variation (Hinton \& Pollock, 2000). Of course, some of the folk perceptions likely do not line up with actual dialectal differences, although it is sometimes difficult to tell without the appropriate type of production data. For example, some of the greetings were attributed to certain states, when in our experience they seem to be used more widely (e.g., what it is?, which one participant associated with Indiana). The URR variable was also attributed to a wider range of places than where linguists have presently documented it (Hinton \& Pollock, 2000; Blake \& Shousterman, 2010).

The participants' comments about languages or dialects other than AAE also show how highly attuned they are to the linguistic and cultural diversity of the US. Comments about "Geechie," "islander," and "French" influence in different parts of the South seem to speak to their awareness of diversity within black American culture, and there were also mentions of Cajun speech and Spanish as well as comparisons to both "proper" and "country" white speech. Terms such as diversity, melting pot, and multicultural were also commonly used. This sensitivity to diversity likely has two sources. First, many of the participants in this study were highly mobile, and thus had considerable exposure to the speech of different regions. This mobility is common among African Americans more generally (Tolnay, 2003), and in this study it was also reflected in how the "Southern" speech label was extended well outside of the traditional boundaries of the South (e.g., to Chicago and Ohio). Second, as African Americans recruited from working class neighborhoods, they are likely not used to thinking of their own speech as the default or unmarked in US society, unlike their counterparts in most previous perceptual dialectology studies of American English; generally, African Americans are expected to codeswitch and accommodate to other groups, without reciprocation. In contrast, the college students in Lance's (1999:307308) study, for example, made relatively few mentions of other ethnolinguistic groups.

Furthermore, when black speech has been mentioned by participants in previous perceptual dialectology studies, it has generally been described in unflattering ways (e.g., the Bay Area has "intelligent speakers but also a large black contingent," according to a college student in Bucholtz et al. 2007:341). In this study, however, the participants recognized a range of AAE varieties in different regions from "broken" to "proper," and the term "proper" was not always synonymous with "sounding white." The fact that African Americans have multidimensional views of AAE should not be surprising, but their perspectives have rarely been included in sociolinguistic studies.

In summary, regional linguistic and cultural variation was quite salient to the participants of this study. By applying perceptual dialectology methods in the field, the study was able to reflect African American experiences with language variation in the US, rather than relying on researchers' intuitions of what AAE is or only examining the folk beliefs of American English speakers from privileged groups. This research provides new perspective on the perceptions of African Americans in Ohio concerning AAE, which is valuable 
both in its own right, and also as a point of comparison with other studies. Further production and perception studies are needed to document AAE regional variation more fully, and perceptual dialectology has proven to be a useful tool for accessing speakers' beliefs about where and how it varies.

\section{Acknowledgments}

This paper was originally presented at the 2014 annual meeting of the American Dialect Society. We are grateful to everyone who participated in the survey and to the Ohio State Department of Linguistics for providing funds for the study.

\section{Notes}

1 In this paper, we use African American English (AAE) as a cover term for different varieties of African American speech. While the majority of research on AAE focuses on the vernacular, the participants in this study were asked about their perceptions of "Black English/African American English," which for them may have encompassed a range of vernacular and standard varieties.

2 Irvine (2004:65-69) makes a similar argument about variation in acrolectal Jamaican English. Because educated Jamaicans learn standard English grammar in school, there is little morphosyntactic variation in their speech. However, there is still variation in their accents, and "good" English speakers are distinguished by their use of certain phonological variables.

3 We asked participants about their familiarity with Black English/AAE rather than if they spoke it themselves because "do you speak Black English?" is a potentially face-threatening question. Phrasing the question this way allowed us to roughly gauge their passive competence in $\mathrm{AAE}$, and it framed the task as a discussion of other people's speech rather than as an evaluation of their own.

4 This analysis does not include two instances in which a participant (\#41) just said East/West without marking the states included under these umbrella terms.

5 We used the default methods for both dist() and hclust().

6 Throughout this paper, comments quoted from participant maps will be italicized, followed by the ID number of the participant and the parts of the map to which the comment applies.

7 This map does not include one mention of bro that was attributed to "the East" without indicating the boundaries of that region.

8 The map does not include a participant who gave a non-rhotic example for an unspecified "East" (\#41).

\section{References}

Blake, Renée \& Cara Shousterman. 2010. Diachrony and AAE: St. Louis, hip-hop, and sound change outside of the mainstream. Journal of English Linguistics 38(3). 230-247.

Blavity Team. 2016. 26 black men greetings that will have you in your feels: \#BlackMenGreetings. Blavity. http:/ / blavity. com/black-men-greetings/ (4 March 2016).
Bucholtz, Mary, Nancy Bermudez, Victor Fung, Lisa Edwards \& Rosalva Vargas. 2007. Hella Nor Cal or totally So Cal? The perceptual dialectology of California. Journal of English Linguistics 35(4). 325-352.

Campbell-Kibler, Kathryn. 2012. Contestation and enregisterment in Ohio's imagined dialects. Journal of English Linguistics 40(3). 281-305.

Carpenter, Jeannine. 2005. The invisible community of the lost colony: African American English on Roanoke Island. American Speech 80(3). 227-256.

Carver, Craig. 1987. American regional dialects: A word geography. Ann Arbor: University of Michigan Press.

Charity, Anne H. 2007. Regional differences in low SES African American children's speech in the school setting. Language Variation and Change 19(3). 219-248.

Childs, Becky \& Christine Mallinson. 2004. African American English in Appalachia: Dialect accommodation and substrate influence. English World-Wide 25(1). 27-50.

Daan, Jo C. 1999. Dialects. In Dennis R. Preston (ed.), Handbook of perceptual dialectology, Volume 1, 9-30. Amsterdam: John Benjamins Publishing Company.

Durian, David, Robin Dodsworth \& Jennifer Schumacher. 2010. Convergence in blue collar Columbus, OH African American and White vowel systems? In Malcah Yeager-Dror \& Erik R. Thomas (eds.), African American English speakers and their participation in local sound changes: A comparative study, 161-190. Publication of the American Dialect Society, 94. Durham: Duke University Press.

Eberhardt, Maeve. 2008. The low-back merger in the Steel City: African American English in Pittsburgh. American Speech 83(3). 284-311.

Fasold, Ralph W. \& Walt Wolfram. 1970. Some linguistic features of Negro dialect. In Ralph W. Fasold \& Roger W. Shuy (eds.), Teaching Standard English in the inner city, 41-86. Washington, DC: Center for Applied Linguistics.

Feagin, Crawford. 2000. Sound change in the South. American Speech 75(4). 342-344.

Fought, Carmen. 2002. California students' perceptions of, you know, regions and dialects? In Daniel Long \& Dennis R. Preston (eds.), Handbook of perceptual dialectology, Volume 2, 113-134. Amsterdam: John Benjamins Publishing Company.

Fought, Carmen. 2006. Language and ethnicity. Cambridge: Cambridge University Press.

Fought, Carmen. 2013. Ethnicity. In J.K. Chambers \& Natalie Schilling-Estes (eds.), The handbook of language variation and change, 388-406. Malden, MA: Wiley-Blackwell.

Fridland, Valerie. 2003. Network strength and the realization of the Southern Vowel Shift among African Americans in Memphis, Tennessee. American Speech 78(1). 3-30.

Fridland, Valerie \& Kathryn Bartlett. 2006. The social and linguistic conditioning of back vowel fronting across ethnic groups in Memphis, Tennessee. English Language and Linguistics 10(1). 1-22.

Green, Lisa J. 2002. African American English: A linguistic introduction. Cambridge: Cambridge University Press.

Hartley, Laura C. 1999. A view from the West: Perceptions of US dialects by Oregon residents. In Dennis R. Preston (ed.), Handbook of perceptual dialectology, Volume 1, 315-332.

Amsterdam: John Benjamins Publishing Company. 
Hinton, Linette N. \& Karen E. Pollock. 2000. Regional variations in the phonological characteristics of African American Vernacular English. World Englishes 19(1). 59-71.

Hutcheson, Neal (producer). 2005. Voices of North Carolina. Raleigh, NC: North Carolina Language and Life Project.

Irvine, Alison. 2004. A good command of the English language: Phonological variation in the Jamaican acrolect. Journal of Pidgin and Creole Languages 19(1). 41-76.

Kolker, Andrew \& Louis Alvarez. 1987. American tongues. New York: Center for New American Media.

Kuiper, Lawrence. 1999. Variation and the norm: Parisian perceptions of regional French. In Dennis R. Preston (ed.), Handbook of perceptual dialectology, Volume 1, 243-262. Amsterdam: John Benjamins Publishing Company.

Labov, William. 1972. Language in the inner city: Studies in the Black English Vernacular. Philadelphia: University of Pennsylvania Press.

Labov, William, Sharon Ash \& Charles Boberg. 2006. The atlas of North American English: Phonetics, phonology and sound change. Berlin: Mouton de Gruyter.

Labov, William, Paul Cohen, Clarence Robins \& John Lewis. 1968. A study of the non-Standard English of Negro and Puerto Rican speakers in New York City. Washington, DC: United States Office of Education Final Report, Research Project 3288.

Lance, Donald M. 1999. Regional variation in subjective dialect divisions in the United States. In Dennis R. Preston (ed.), Handbook of perceptual dialectology, Volume 1, 283-314. Amsterdam: John Benjamins Publishing Company.

Lanehart, Sonja L. (ed.) 2015. The Oxford handbook of African American language. Oxford: Oxford University Press.

Legum, Stanley E., Carole Pfaff, Gene Tinnie \& Michael Nichols. 1971. The speech of young black children in Los Angeles. Inglewood, CA: Southwest Regional Laboratory.

Lesho, Marivic \& Eeva Sippola. 2014. Folk perceptions of variation among the Chabacano creoles. Revista de Crioulos de Base Lexical Portuguesa e Espanhola 5. 1-46.

Lippi-Green, Rosina. 1997. English with an accent: Language, ideology, and discrimination in the United States. London: Routledge.

Long, Daniel. 1999. Mapping nonlinguists' evaluations of Japanese language variation. In Dennis R. Preston (ed.), Handbook of perceptual dialectology, Volume 1, 199-226. Amsterdam: John Benjamins Publishing Company.

Minoff, Annie. 2013. The Chicago accent and the Chicago 'blaccent'. Chicago: Curious City, WBEZ91.5. http://www. wbez.org/series/curious-city/chicago-accent-and-chicago\%E2\%80\%98blaccent $\%$ E2\%80\%99-107040 (3 June 2015).

Morgan, Marcyliena. 1994. The African-American speech community: Reality and sociolinguistics. In Marcyliena Morgan (ed.), Language and the social construction of identity in creole situations, 121-148. Los Angeles: Center for Afro-American Studies, UCLA.

Niedzielski, Nancy. 2002. Attitudes toward Midwestern American English. In Daniel Long \& Dennis R. Preston (eds.), Handbook of perceptual dialectology, Volume 2, 321-327. Amsterdam: John Benjamins Publishing Company.

Niedzielski, Nancy A. \& Dennis R. Preston. 2003. Folk linguistics. Berlin: Mouton de Gruyter.
Ogbu, John U. 1999. Beyond language: Ebonics, proper English, and identity in a Black-American speech community. American Educational Research Journal 36(2). 147-184.

Preston, Dennis R. 1986. Five visions of America. Language in Society 15(2). 221-240.

Preston, Dennis. 2002. Perceptual dialectology: Aims, methods, findings. In Jan Berns \& Jaap van Marle (eds.), Present-day dialectology: Problems and findings, 57-104. Berlin: Mouton de Gruyter.

Rahman, Jacquelyn. 2008. Middle-class African Americans: Reactions and attitudes toward African American English. American Speech 83(2). 141-176.

Rickford, John R. \& Russell John Rickford. 2000. Spoken soul: The story of Black English. New York: Wiley.

Risdal, Megan L. \& Mary E. Kohn. 2014. Ethnolectal and generational differences in vowel trajectories: Evidence from African American English and the Southern Vowel System. University of Pennsylvania Working Papers in Linguistics 20(2). 138-148.

Rowe, Ryan D. 2005. The development of African American English in the oldest Black town in America: -s absence in Princeville, North Carolina. Raleigh, NC: North Carolina State University MA thesis.

Spears, Arthur K. 1988. Black American English. In Johnetta B. Cole (ed.), Anthropology for the nineties: Introductory readings, 96-113. New York: Free Press.

Suárez Büdenbender, Eva-Maria. 2011. Puerto Ricans' evaluations of Dominicans and Dominican Spanish as reflected in inter-personal interviews. Southwest Journal of Linguistics 30(2). 101-135.

Thomas, Erik R. 1989. Vowel changes in Columbus, Ohio. Journal of English Linguistics 22(2). 205-215.

Thomas, Erik R. 2007. Phonological and phonetic characteristics of African American Vernacular English. Language and Linguistics Compass 1(5). 450-475.

Thomas, Erik R. \& Jeffrey Reaser. 2004. Delimiting perceptual cues used for the ethnic labeling of African American and European American voices. Journal of Sociolinguistics 8(1). 54-87.

Thomas, Erik R. \& Alicia Beckford Wassink. 2010. Variation and identity in African-American English. In Carmen Llamas \& Dominic Watts (eds.), Language and identities, 157-165. Edinburgh: Edinburgh University Press.

Tolnay, Stewart E. 2003. The African American "Great Migration" and beyond. Annual Review of Sociology 29 209-232.

Wassink, Alicia Beckford. 1999. Historic low prestige and seeds of change: Attitudes toward Jamaican Creole. Language in Society 28(1). 57-92.

Weldon, Tracey L. 2015. Sounding Black: Labeling and perceptions of African American voices on Southern college campuses. Paper presented at Language Variety in the South: The New South (LAVIS IV), Raleigh, North Carolina, 11 April 2015.

Winford, Donald. 1976. Teacher attitudes toward language varieties in a creole community. International Journal of the Sociology of Language 8. 45-76.

Winford, Donald. 2000. Plus ça change: The state of studies in African American English. American Speech 75(4). 409-411. 
Wolfram, Walt. 2007. Sociolinguistic folklore in the study of African American Vernacular English. Language and Linguistic Compass 1(4). 293-313.

Wolfram, Walter A. 1969. A sociolinguistic description of Detroit Negro speech, Urban Language Series, No. 5. Washington, DC: Center for Applied Linguistics.

Wolfram, Walt \& Mary E. Kohn. 2015. Regionality in the development of African American English. In Sonja L. Lanehart (ed.), The Oxford handbook of African American language, 140-162. Oxford: Oxford University Press.
Wolfram, Walt \& Natalie Schilling-Estes. 1998. American English: Dialects and variation. Malden, MA: Blackwell Publishers.

Wolfram, Walt \& Erik R. Thomas. 2002. The development of African American English, Malden, MA: Blackwell.

Yeager-Dror, Malcah \& Erik R. Thomas (eds.) 2010. African American English speakers and their participation in local sound changes: A comparative study. Publication of the American Dialect Society, 94. Durham, NC: Duke University Press. 